http://jmscr.igmpublication.org/home/ ISSN (e)-2347-176x ISSN (p) 2455-0450 crossref DOI: https://dx.doi.org/10.18535/jmscr/v7i10.129

\title{
Four Tonometers and their correlation- A comparative study
}

\author{
Authors \\ Prasanthi $\mathbf{M}^{1}$, Suganya $\mathrm{E}^{2^{*}}$, Ravikumar $\mathbf{R}^{3}$ \\ ${ }^{1}$ Assistant Professor, Dept. of Ophthalmology, TMCH, Chennai, India \\ ${ }^{2}$ Assistant Professor, Dept. of Community Medicine, TMCH, Chennai, India \\ ${ }^{3}$ Professor and Head, Dept. of Ophthalmology, TMCH, Chennai, India \\ *Corresponding Author \\ Dr Suganya E \\ Assistant Professor, Dept. of Community Medicine, TMCH, Chennai, India
}

\begin{abstract}
Background: Early identification of Ocular Hypertension is needed to prevent and control the life threatening glaucoma.

Objectives

1. To compare the Intra ocular pressure assessed by using GAT, Schiotz, Tonopen and Non Contact Tonometer (NCT)

2. To correlate the Schiotz, Tonopen and NCT tonometers with GAT in measuring the IOP

Materials and Methods: Cross-sectional study conducted in Ophthalmology department of SSSIHMS, Andhra Pradesh for a period of 2 months.112 study participants were included in the study and their IOP was assessed using GAT, Schiotz, Tonopen and NCT tonometers and the readings were compared. Statistical analysis was done using Pearson correlation and p value

Results: The mean age of the participants was $53.20 \pm 13.03$ years. Most of them are males $66(58.9 \%)$, illiterates 50(44.7\%) and they belonged to Class I socio-economic status 49(43.7\%). The average intra ocular pressure was high in females than males. There was a difference in average IOP between Right eye and Left eye measured using the 4 different tonomters. The mean IOP in left eye was high compared to Right eye, measured using NCT, Tonopen and Schiotz. However the GAT measurement in contrary showed high $I O P$ in Right eye comparing the left eye Pearson correlation showed a moderate positive correlation between the 4 tonometric assessments, having $r$ value of 0.577 and it was statistically significant.

Conclusion: Positive correlation between the tonometric readings gives the future consideration in using various tonometers for IOP measurements.
\end{abstract}

Keywords: Schiotz tonometer, GAT,NCT, Tonopen, Glaucoma.

\section{Introduction}

Ocular hypertension is the important modifiable risk factor of a life threatening disease called glaucoma. ${ }^{1}$ Globally millions of people were affected with glaucoma, every year. ${ }^{2}$ Decrease in Intra ocular pressure (IOP) can delay the damage caused by glaucoma. ${ }^{3}$ Thus assessment of IOP has a vital role in diagnosis, treatment and even in control of the complications of glaucoma. ${ }^{1,3}$ Tonometers are the instruments used for measuring IOP. Among the various tonometers, Goldmann Applanation tonometry (GAT) is considered as the gold standard for measuring IOP. ${ }^{4}$ However Applanation 
Tonometry has known limitations like influence of Central Corneal Thickness (CCT) and corneal curvature, necessity to support the upper lid during measurement, use of topical anaesthesia and fluorescein staining of the tear film, hence it is often unsuitable for field surveys settings. ${ }^{5}$ Various other tonometers available are Schiotz, Tonopen and Non Contact Tonometer (NCT). Schiotz tonometer is a prototype of indentation tonometer. It is portable, sturdy, relatively inexpensive and easy to operate.

The non-contact tonometer applanates the cornea by a jet of air, so there is no direct contact between the device and the surface of the eye, but, the disadvantage is that it cannot be used for the measurement of irregular corneas. ${ }^{6}$ The Tono-Pen tonometer was developed for use in patients who present with the sort of measurement problems that are often associated with children. The instrument is easy to handle, portable, light weight, and does not require the use of fluorescein. ${ }^{7}$

With the above background the study aims at comparing 3 different types of tonometers namely Schiotz, NCT and Tonopen against the gold standard Goldmann applanation tonometer (GAT) in measuring the IOP and to assess the correlation between them.

\section{Objectives}

1. To compare the Intra ocular pressure assessed by using GAT, Schiotz, Tonopen and Non Contact Tonometer (NCT)

2. To correlate the Schiotz, Tonopen and NCT tonometers with GAT in measuring the IOP

\section{Materials and Methods}

This study is a part of DNB ophthalmology thesis. It is a cross-sectional study, conducted in outpatient section of Department of Ophthalmology, Sri Sathya Sai Institute of Higher Medical Sciences (SSSIHMS) Prasanthigram, Anantapur district, Andhra Pradesh, India. Only those patients reported to the outpatient department from April 2011 to April 2012 were included in the study. The study population included where those, patients presenting to the eye clinic of SSSIHMS, aged above 15 years, without any active intraocular inflammation having normal intraocular pressure, without any systemic illness.

\section{Results}

Out of 112 study participants, maximum number of participants were aged $>50$ years $(57.2 \%)$, the mean age of the participants was $53.20 \pm 13.03$ and most of them were males $66(58.9 \%)$. It was also noted that nearly half of them were Illiterate $(44.7 \%)$ and only less than $5 \%$ of them were graduated. According to modified kuppusamy scale classification, most $(43.7 \%)$ of them belonged to Class I socio-economic status [Table 1]

The average intra ocular pressure was high in females than males, the IOP values close to that measured by GAT was that measured with Schiotz, The IOP measured with GAT, Schiotz, Tonopen and NCT in females and males are $15.14 \mathrm{~mm}$ of $\mathrm{Hg}, 14.99 \mathrm{~mm}$ of $\mathrm{Hg}, 13.71 \mathrm{~mm}$ of $\mathrm{Hg}, 12.64 \mathrm{~mm}$ of $\mathrm{Hg}$ and $15.02 \mathrm{~mm}$ of $\mathrm{Hg}, 14.36 \mathrm{~mm}$ of $\mathrm{Hg}, 12.94 \mathrm{~mm}$ of $\mathrm{Hg}$ and $12.37 \mathrm{~mm}$ of $\mathrm{Hg}$ respectively[Figure 1]

There was a difference in average IOP between Right eye and Left eye measured using the 4 different tonomters. The mean IOP in left eye was high compared to Right eye, measured using NCT, Tonopen and Schiotz. However the GAT measurement in contrary showed high IOP in Right eye comparing the left eye [Table 2]

All the three tonometers namely NCT, Tonopen and Schiotz had positive correlation in measuring the Intra ocular pressure as with IOP measured using GAT. The $r$ value determined showed positive correlation. The $r$ value found out for measuring IOP using NCT, in relation to GAT assessment was high compared to those measured with Tonopen and Schiotz and it was found statistically significant having a $p$ value of $<0.001$. [Table 3] 
Table 1: Distribution of participants based on socio-demographic variables $(n=112)$

\begin{tabular}{|l|c|}
\hline PARAMETERS & FREQUENCY (\%) \\
\hline AGE (in years) & $3(2.6 \%)$ \\
$<30$ & $45(40.2 \%)$ \\
$30-50$ & $64(57.2 \%)$ \\
\hline 50 & \\
\hline Mean \pm SD: 53.20 \pm 13.03 & \\
\hline SEX & $66(58.9 \%)$ \\
Males & $46(41.1 \%)$ \\
Females & \\
\hline EDUCATION & $50(44.7 \%)$ \\
Illiterate & $32(28.6 \%)$ \\
Primary/Secondary & $25(22.3 \%)$ \\
High school/Higher Sec & $5(4.5 \%)$ \\
Graduates and above & \\
& \\
\hline Socio-economic status & $49(43.7 \%)$ \\
Class I & $21(18.7 \%)$ \\
Class II & $17(15.1 \%)$ \\
Class III & $25(22.3 \%)$ \\
Class IV &
\end{tabular}

Table 2: Comparison of IOP measurements between Right Eye and Left Eye using GAT, SCHIOTZ, NCT and TONOPEN tonometers $(n=112)$

\begin{tabular}{|c|c|c|c|c|c|}
\hline & & Measurement1 & Measurement2 & Measurement3 & Average \\
\hline \multicolumn{6}{|c|}{ Right eye } \\
\hline$\square$ & NCT & $12.25 \pm 2.86$ & $12.31 \pm 2.80$ & $12.44 \pm 2.68$ & $12.33 \pm 2.68$ \\
\hline$\square$ & TONOPEN & $13.03 \pm 3.68$ & $12.93 \pm 3.29$ & $13.07 \pm 3.77$ & $13.01 \pm 3.16$ \\
\hline$\square$ & GAT & $14.99 \pm 3.12$ & $15.21 \pm 2.98$ & $15.52 \pm 3.06$ & $15.24 \pm 3.00$ \\
\hline$\square$ & SCHIOTZ & $14.29 \pm 3.44$ & $14.06 \pm 3.24$ & $13.88 \pm 3.33$ & $14.04 \pm 3.24$ \\
\hline \multicolumn{6}{|c|}{ Left eye } \\
\hline$\square$ & NCT & $12.54 \pm 3.22$ & $12.66 \pm 3.26$ & $12.69 \pm 3.12$ & $12.63 \pm 3.10$ \\
\hline$\square$ & TONOPEN & $13.29 \pm 3.69$ & $13.31 \pm 3.83$ & $13.90 \pm 4.00$ & $13.50 \pm 3.49$ \\
\hline$\square$ & GAT & $14.68 \pm 3.29$ & $14.95 \pm 3.19$ & $15.06 \pm 3.27$ & $14.90 \pm 3.17$ \\
\hline$\square$ & SCHIOTZ & $14.70 \pm 3.63$ & $14.48 \pm 3.82$ & $14.53 \pm 3.65$ & $14.58 \pm 3.54$ \\
\hline
\end{tabular}


Table 3: Correlation and paired t test interpretation

\begin{tabular}{|l|c|c|}
\hline & $\begin{array}{c}\text { Pearson } \\
\text { Correlation }\end{array}$ & P value \\
\hline NCT vs GAT & 0.593 & $<0.001^{* *}$ \\
\hline TONOPEN vs GAT & 0.567 & $<0.001^{* *}$ \\
\hline SCHIOTZ vs GAT & 0.577 & $<0.001^{* *}$ \\
\hline
\end{tabular}

Figure 1: Comparison of IOP between males and females $(n=112)$

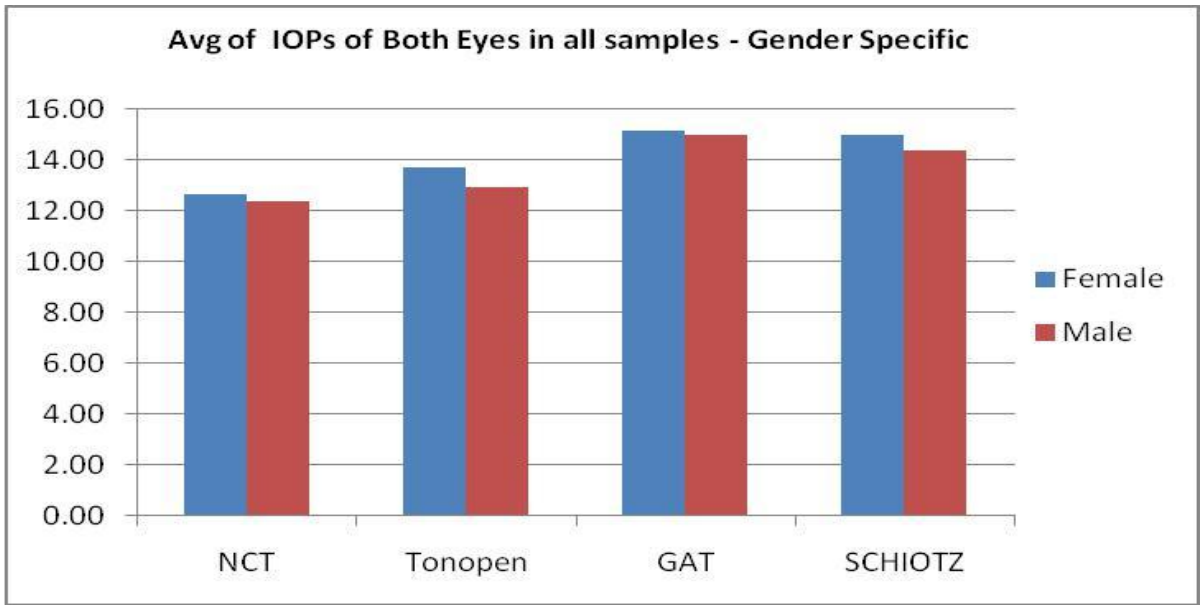

\section{Discussion}

Ocular hypertension being an important indicator of Glaucoma, has to be identified at the earliest. This study compares IOP measured using 4 different tonometers. The mean IOP measured using the goldstandard tonometric assessment was $15.24 \pm 3.00$ in Right eye and 14.90 \pm 3.17 in left eye respectively. In a study conducted by Schreiber $\mathrm{W}$ et $\mathrm{al}^{8}$ the mean IOP (GAT) was 13.2+/-3.0 mmHg, which was less compared to our present study findings

Hessemer $\mathrm{V}$ etal ${ }^{9}$ compared a new hand-held tonometer, Tono-Pen with the Goldmann tonometer and found that TONOPEN slightly overestimated the IOP by a maximum of $1.48 \mathrm{~mm} \mathrm{Hg}$. We observed that there was statistically significant difference in the values of intraocular pressures between Tonopen and GAT.

Schiotztomoter often generated a relatively high reading of IOP and in that case the patient must be assessed using GAT, before diagnosing them to have high intra ocular pressure. ${ }^{10}$ In our present study, Schiotztonometric IOP reading is less than the IOP reading obtained by using GAT. The mean IOP measured in Right and Left eye using GAT $(15.24 \pm 3.00 \mathrm{~mm}$ of $\mathrm{Hg}$ and $14.90 \pm 3.17 \mathrm{~mm}$ of $\mathrm{Hg}$ ) and schiotz in Right and left eye are 14.04 $\pm 3.24 \mathrm{~mm}$ of $\mathrm{Hg}$ and $14.58 \pm 3.54 \mathrm{~mm}$ of $\mathrm{Hg}$ respectively. This study finding was in agreement with the previous study conducted by Armalayetal ${ }^{11}$

Jonathan SP, in his study, mentioned that, for either gender, the absolute mean level of IOP remains little altered from childhood into and throughout adulthood. However the physiological basis for these observations remains obscure. In this study also the intra ocular pressures in female subjects were found to be more than males. The above study is in perfect agreement with our study. ${ }^{12}$

In a study done by Vinayak et al, 248 eyes of 60 healthy subjects, 31 patients with POAG, 16 patients with PACG \& 17 patients with OHT underwent IOP evaluation with NCT, GAT \& Schiotz tonometer). Finally they concluded that IOP as recorded by the three tonometers was not statistically significantly different from each other, 
so any of these tonometers can be safely used for routine glaucoma workup. This study was in perfect agreement with our study. ${ }^{13}$

Rateb $\mathrm{M}$ et $\mathrm{al}^{14}$ in their study concluded that there was no significant correlation between the IOP measurements done using different tonometers, this was contrary to our present study finding, which showed a significant positive correlation between the measurements

\section{Conclusion}

Glaucoma being an eye threatening condition, has to be identified earlier. GAT, is the gold standard assessment tool for IOP measurement, however an alternate method has to be available to overcome its limitation.

Present study, infers that the IOP difference measured using GAT and Schiotz is insignificant, which concludes that Schiotz can also be used as an standard IOP assessment instrument and also the significant positive correlation between the various tonometric readings gives a positive insight on using the various tonometers for measuring IOP.

\section{Acknowledgement}

We would like to sincerely thank the participants of our study, for their interest and co-operation.

\section{References}

1. Gordon MA, Beiser JA, Brandt JA, et al. The Ocular Hypertension treatment Study: baseline factors that predict the onset of primary open-angle glaucoma. Arch Ophthalmol. 2002; 120(6):714-720.

2. Bell JA, Roy H: Primary open angle glaucoma.

http:/emedicine.medscape.com/article/ 120617-overview (accessed June 2013)

3. American Academy of Ophthalmology, BCSC. Section 10. Glaucoma. 2009-10.

4. Tonnu PA, Ho T, Sharma K: A comparison of four methods of tonometry: method agreement and inter observer variability. $\mathrm{Br} \mathrm{J}$ Ophthalmol 2005,89:847-850
5. Bandyopadhyay $\mathrm{M}$, Raychaudhuri $\mathrm{A}$ : Comparison of Golsmann applanation tonometry with the Tonopen for measuring intraocular pressure in a population-based glaucoma survey in rural West Bengal. Ophthalmic Epidemiol 2002;9:215-224

6. Becker-schaffers. Diagnosis and therapy of glaucomas , 8th edition

7. Frenkel REP, Hong YJ, Shin DH. Comparison of the Tono-Pen to the Goldmann applanation tonometer. Arch Ophthalmol 1988,106: 75053.

8. Schreiber W etal. A comparison of rebound tonometry (ICare) with TonoPenXL and Goldmann applanation tonometry, ophtahlmology 2007 Apr;104 (4):299-304.

9. Hessemer V, Rössler R. comparison of a new hand-held tonometer, Tono-Pen (TP) with the Goldmann tonometer (GM); Klin Monatsbl Augenheilkd 1988; 193(10):420-426.

10. Stevens S. How to measure intraocular pressure: Schiötz tonometry. Community Eye Health. 2008;21(66):34.

11. Armaly MF, Salamoun SG. Schiotz and Applanation Tonometry. Arch Ophthalmol. 1963;70(5):603-609

12. Jonathan SP. Evidence that a gender difference is present from childhood. Ophthalmic and physiological optics. Volume 20, Issue 2, 15 March 2000, Pages 131-136

13. Vinayak Bhatia, Harsh Kumar. Comparison of the Goldmann-applanation, Schiotz impression \& noncontact tonometers in different glaucoma patients \& the effect of central corneal thickness. 10th EGS congress, Copenhagen. JUNE 17-22,2012.

14. Rateb M, Abdel-Radi M, Eldaly Z, Elmohamady MN, Noor El Din A. Comparison of IOP Measurement by Goldmann Applanation Tonometer, IC are Rebound Tonometer, and Tono-Pen in Keratoconus Patients after Myo Ring Implantation. Journal of Ophthalmology 2019;2019:7. 